\title{
European Association of Urology Position Paper on the Prevention of Infectious Complications Following Prostate Biopsy
}

\author{
Adrian Pilatz $^{a, *}$, Rajan Veeratterapillay ${ }^{b}$, Konstantinos Dimitropoulos $^{c}$, \\ Muhammad Imran Omar ${ }^{d}$, Benjamin Pradere ${ }^{e, f}$, Yuhong Yuan ${ }^{g}$, Tommaso Cai ${ }^{h}$, \\ Tunde Mezei $^{i}$, Wout Devlies ${ }^{j}$, Franck Bruyère ${ }^{e, f}$, Riccardo Bartoletti $^{k}$, Bela Köves ${ }^{l}$, \\ Suzanne Geerlings ${ }^{m}$, Sören Schubert ${ }^{n}$, Jeremy Grummet ${ }^{o}$, Nicolas Mottet $^{p}$, \\ Florian Wagenlehner $^{a}$, Gernot Bonkat ${ }^{q}$
}

\begin{abstract}
a Department of Urology, Pediatric Urology and Andrology, Justus-Liebig-University Giessen, Giessen, Germany; ${ }^{\mathrm{b}}$ Freeman Hospital, Newcastle Upon Tyne, UK; ${ }^{\mathrm{c}}$ Department of Urology, Aberdeen Royal Infirmary, Aberdeen, Scotland, UK; ${ }^{\mathrm{d}}$ Guidelines Office, European Association of Urology, Arnhem, The Netherlands; ${ }^{\mathrm{e}}$ Department of Urology, CHRU Bretonneau, Tours, France; ${ }^{\mathrm{f}}$ Université Francois Rabelais, PRES Centre Val de Loire, Tours, France; ${ }^{\mathrm{g}}$ Department of Medicine, Division of Gastroenterology, McMaster University, Hamilton, Canada; ${ }^{\mathrm{h}}$ Department of Urology, Santa Chiara, Reg. Hospital, Trento, Italy; ${ }^{\mathrm{i}}$ Department of Urology, Telemark Hospital, Skien, Norway; ${ }^{\mathrm{j}}$ Department of Urology, UZ Leuven, Leuven, Belgium; ${ }^{\mathrm{k}}$ Department of Translational Research and New Technologies, University of Pisa, Italy; ${ }^{1}$ Department of Urology, South-Pest Teaching Hospital, Budapest, Hungary; ${ }^{\mathrm{m}}$ Department of Internal Medicine, Amsterdam University Medical Center, The Netherlands; ${ }^{\mathrm{n}}$ Max von Pettenkofer Institute, Faculty of Medicine, LMU Munich, Germany; ${ }^{\circ}$ Department of Surgery, Alfred Health, Central Clinical School, Monash University, Melbourne, Australia; ${ }^{\mathrm{P}}$ Department of Urology, University Jean Monnet St Etienne, Saint-Étienne, France; ${ }^{9}$ Alta Uro AG, Merian Iselin Klinik, Center of Biomechanics and Calorimetry, University Basel, Basel, Switzerland
\end{abstract}

The European Association of Urology (EAU) Urological Infections Guidelines Panel has recently published a large two-part systematic review (SR) and meta-analysis (MA) of randomized controlled trials (RCTs) on the use of antibiotic and nonantibiotic interventions for the prevention of infectious complications related to prostate biopsies (PBs) $[1,2]$. The aim of this article is to summarize the available evidence and provide clinicians with practical recommendations on how to reduce infection rates after PB (Fig. 1).

\section{The right indication for PBs and how to minimize unnecessary biopsies}

The indication for a $\mathrm{PB}$ is based on prostate-specific antigen (PSA) level and/or suspicious digital rectal examination and/ or imaging. The decision to perform a biopsy should be taken following a PSA control ideally performed in the same laboratory as the original test. The patient's age, existing comorbidities, and risk stratification should also be considered [3]. With the wide availability of and increasing experience with prostate magnetic resonance imaging (MRI), there is growing evidence that MRI diagnostics can be used to prevent unnecessary PBs and their associated complications [4]. Explicitly, an MA of six RCTs showed that antibiotic therapy for PSA reduction is unhelpful and does not prevent unnecessary biopsies [5].

\section{Patients at risk of developing postbiopsy infections}

Personalized medicine plays a crucial role in contemporary clinical practice. In patients who require PBs, personalized medicine requires identifying men at high risk for biopsyrelated infectious complications beforehand and adapting management accordingly. This will reduce periprocedural morbidity and mortality rates.

The EAU SR and MA summarized evidence from a total 143 RCTs reporting multiple risk factors (Supplementary

\footnotetext{
* Corresponding author at: Department of Urology, Pediatric Urology and Andrology, Justus Liebig University Giessen, Rudolf-Buchheim-Str. 7, 35392, Giessen, Germany.

E-mail address: adrian.pilatz@chiru.med.uni-giessen.de (A. Pilatz).
} 


\section{Prostate biopsy workflow to reduce infectious complications}

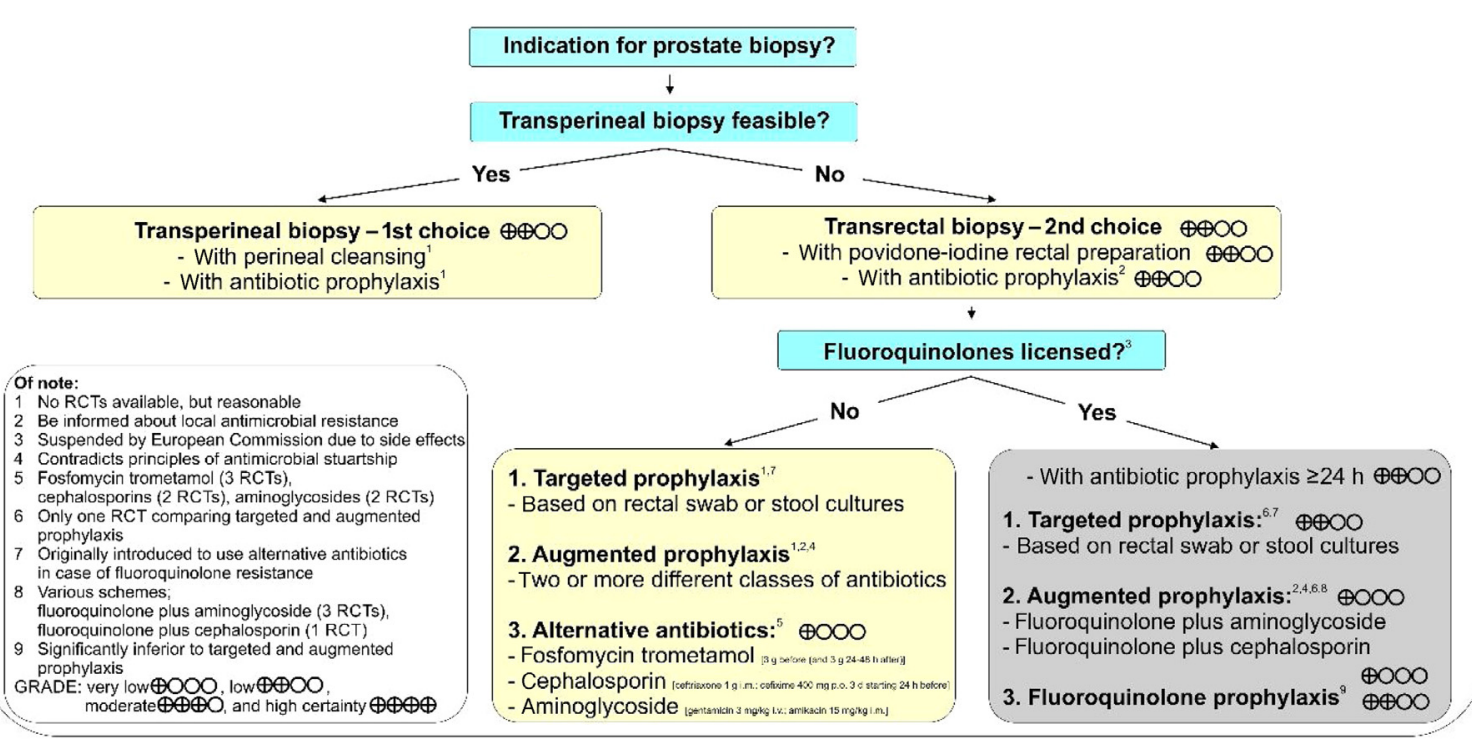

Fig. 1 - Suggested workflow on how to reduce postbiopsy infections. GRADE Working Group grades of evidence: high certainty ( $\oplus \oplus \oplus$ )-we are very confident that the true effect lies close to that of the estimate of the effect; moderate certainty ( $\oplus \oplus \oplus \ominus)$-we are moderately confident in the effect estimate, that is, the true effect is likely to be close to the estimate of the effect, but there is a possibility that it is substantially different; low certainty $(\oplus \oplus \ominus \ominus$-our confidence in the effect estimate is limited, that is, the true effect may be substantially different from the estimate of the effect; very low certainty $(\oplus \ominus \ominus \ominus)$-we have very little confidence in the effect estimate, that is, the true effect is likely to be substantially different from the estimate of effect.

RCT = randomized controlled trial.

Table 1). A notable variation in reported risk factors was observed across the studies. Although some of the studies randomized patients with risk factors into different arms, clear recommendations on the practical management of patients at high risk for PB complications based on risk stratification could not be provided $[1,2]$.

\section{Why you should use transperineal biopsy}

An MA of seven RCTs showed that transperineal PBs were associated with significantly fewer infectious complications (risk ratio [RR] 0.55, 95\% confidence interval [CI]: 0.33-0.92) compared with transrectal PBs [2]. In addition, an SR including 165 studies with 162577 patients described sepsis rates of $0.1 \%$ and $0.9 \%$ for transperineal and transrectal PBs, respectively [6]. A population-based study from the $\operatorname{UK}(n=73630)$ showed lower readmission rates for sepsis in patients who had transperineal versus transrectal PBs (1.0\% vs $1.4 \%$ ) [7].

These results are not surprising, as they align with the surgical principle that the least contaminating approach should be followed in order to reduce the rate of infectious complications. Available evidence highlights that it is time for the urological community to switch from a transrectal to a transperineal PB approach despite any possible logistical challenges [8]. To date, no RCT investigating different antibiotic prophylaxis regimens for transperineal PBs has been published; however, some cohort studies have reported intravenous prophylaxis with cefazolin.

\section{Antibiotic prophylaxis in transrectal biopsy-use of fluoroquinolones suspended by the European Commission}

Perioperative antibiotic prophylaxis with fluoroquinolones was the gold standard for many years due to their excellent pharmacokinetics in prostatic tissue and their low resistance rates. However, widespread and uncontrolled usage of fluoroquinolones has resulted in increasingly high resistance rates. Ultimately, the era of fluoroquinolones in PB prophylaxis was brought to an end by the European Commission in March 2019 with the suspension of the indication for perioperative antibiotic prophylaxis due to the risks of chronic severe side effects [9]. This legally binding decision is applicable in all European Union (EU) countries.

If local fluoroquinolone resistance rates are low, fluoroquinolone prophylaxis is possible; however, the use of fluoroquinolones in this setting falls outside the EU directive. Furthermore, no validated fluoroquinolone resistance threshold has been identified. A minimum of a fullday course of fluoroquinolone prophylaxis should be offered, as the MA showed that a single dose was significantly inferior [1]. However, our recent SR showed that empirical prophylaxis with fluoroquinolones was inferior to both targeted (RR 1.81, 95\% CI: 1.28-2.55) and augmented antibiotic prophylaxis (RR 2.10, 95\% CI: $1.53-$ 2.88) [1]. 
Table 1 - Overview of randomized controlled trials investigating standard prophylaxis versus augmented prophylaxis.

\begin{tabular}{|c|c|c|c|c|c|c|c|}
\hline \multirow[t]{2}{*}{ Study (year) } & \multirow[t]{2}{*}{ Patients } & \multirow[t]{2}{*}{ Country } & \multirow[t]{2}{*}{ Study period } & \multicolumn{2}{|c|}{ Antibiotic classes } & \multicolumn{2}{|c|}{ Detailed prophylaxis } \\
\hline & & & & Standard & Augmented & Standard & Augmented \\
\hline Bosquet (2006) & 71 vs 85 & Spain & 2004 & Aminoglycoside & $\begin{array}{l}\text { Aminoglycoside plus } \\
\text { fluoroquinolone }\end{array}$ & $\begin{array}{l}\text { TOB } 100 \mathrm{mg} \text { i.v. } \\
30 \mathrm{~min} \text { before and } \\
\text { i.m. } 8 \mathrm{~h} \text { after }\end{array}$ & $\begin{array}{l}\text { TOB } 100 \mathrm{mg} \text { i.v. } 30 \mathrm{~min} \text { before } \\
\text { and i.m. } 8 \mathrm{~h} \text { after plus CIP } \\
500 \mathrm{mg} \text { p.o. bid for } 3 \mathrm{~d} \\
\text { starting } 30 \mathrm{~min} \text { before }\end{array}$ \\
\hline Chan (2012) & 179 vs 188 & China & 2007-2009 & Penicillin & $\begin{array}{l}\text { Penicillin plus } \\
\text { fluoroquinolone }\end{array}$ & $\begin{array}{l}\text { AMC } 1000 \mathrm{mg} \text { p.o. } \\
\text { bid for } 36 \mathrm{~h} \text { starting } \\
2 \mathrm{~h} \text { before }\end{array}$ & $\begin{array}{l}\text { AMC } 1000 \mathrm{mg} \text { plus CIP } \\
250 \mathrm{mg} \text { p.o. bid for } 36 \mathrm{~h} \\
\text { starting } 2 \mathrm{~h} \text { before }\end{array}$ \\
\hline Ergakov (2013) & 40 vs 40 & Russia & 2013 & Fluoroquinolone & $\begin{array}{l}\text { Nitroimidazole plus } \\
\text { azithromycin plus } \\
\text { antifungal azole }\end{array}$ & $\begin{array}{l}\text { PEF } 400 \mathrm{mg} \text { p.o. bid } \\
\text { for } 5 \mathrm{~d} \text { starting } 1 \mathrm{~d} \\
\text { before }\end{array}$ & $\begin{array}{l}\text { SEC/AZM/FLC p.o. qd for } 6 \mathrm{~d} \\
\text { starting } 1 \mathrm{~d} \text { before }\end{array}$ \\
\hline Fahmy (2016) & 202 vs 210 & Egypt & 2012-2015 & Fosfomycin & $\begin{array}{l}\text { Fluoroquinolone plus } \\
\text { nitroimidazole }\end{array}$ & $\begin{array}{l}\text { FOF } 3000 \mathrm{mg} \text { p.o. } \\
1-2 \mathrm{~h} \text { before }\end{array}$ & $\begin{array}{l}\text { CIP } 500 \mathrm{mg} \text { and MTZ } 500 \mathrm{mg} \\
\text { p.o. } 1 \mathrm{~h} \text { before }\end{array}$ \\
\hline Fong (1991) & 47 vs 54 & Canada & 1984-1989 & Cotrimoxazole & $\begin{array}{l}\text { Aminoglycoside plus } \\
\text { nitroimidazole }\end{array}$ & $\begin{array}{l}\text { SXT } 320 / 1600 \mathrm{mg} \\
\text { p.o. } 1 \mathrm{~h} \text { before }\end{array}$ & $\begin{array}{l}\text { NET } 1.5 \mathrm{mg} / \mathrm{kg} \text { i.v. and MTZ } \\
500 \mathrm{mg} \text { p.o. } 1 \mathrm{~h} \text { before }\end{array}$ \\
\hline Izadpanahi (2017) & 225 vs 225 & Iran & 2010-2013 & $\begin{array}{l}\text { Fluoroquinolone } \\
\text { plus nitroimidazole }\end{array}$ & $\begin{array}{l}\text { Fluoroquinolone plus } \\
\text { nitroimidazole plus } \\
\text { cephalosporin plus } \\
\text { aminoglycoside }\end{array}$ & $\begin{array}{l}\text { CIP } 500 \mathrm{mg} \text { p.o. bid } \\
\text { and MTZ } 500 \mathrm{mg} \\
\text { p.o. tid for } 5 \mathrm{~d} \\
\text { starting the day } \\
\text { before }\end{array}$ & $\begin{array}{l}\text { CIP } 500 \mathrm{mg} \text { p.o. bid plus MTZ } \\
500 \mathrm{mg} \text { p.o. tid for } 5 \mathrm{~d} \\
\text { starting the day before plus } \\
\text { CRO } 1 \mathrm{~g} \text { i.v. plus AMK } 5 \mathrm{mg} / \mathrm{kg} \\
\text { i.m. } 30-60 \mathrm{~min} \text { before }\end{array}$ \\
\hline Miyazaki (2016) & 230 vs 217 & Japan & 2007-2009 & Fluoroquinolone & $\begin{array}{l}\text { Fluoroquinolone plus } \\
\text { aminoglycoside }\end{array}$ & LVX p.o. $2 \mathrm{~h}$ before & $\begin{array}{l}\text { LVX p.o. } 2 \mathrm{~h} \text { before plus AMK } \\
30 \text { min i.v. before }\end{array}$ \\
\hline Pace (2012) & 70 vs 65 & Italy & 2010-2011 & Fluoroquinolone & $\begin{array}{l}\text { Fluoroquinolone plus } \\
\text { cephalosporin }\end{array}$ & $\begin{array}{l}\text { CIP } 1000 \mathrm{mg} \text { p.o qd } \\
\text { for } 5 \mathrm{~d} \text { starting the } \\
\text { evening before }\end{array}$ & $\begin{array}{l}\text { CIP } 1000 \mathrm{mg} \text { p.o. qd for } 5 \mathrm{~d} \\
\text { starting the evening before } \\
\text { plus CRO } 1 \mathrm{~g} \text { as periprostatic } \\
\text { nerve block } 15 \mathrm{~min} \text { before } \\
\text { biopsy }\end{array}$ \\
\hline Vaz (1994) & 10 vs 10 & Brazil & Not reported & Fluoroquinolone & $\begin{array}{l}\text { Fluoroquinolone plus } \\
\text { nitroimidazole }\end{array}$ & $\begin{array}{l}\text { LOM } 400 \mathrm{mg} \text { p.o. } \\
\text { qd for } 2 \mathrm{~d} \text { starting } \\
3 \mathrm{~h} \text { before }\end{array}$ & $\begin{array}{l}\text { LOM } 400 \mathrm{mg} \text { p.o. qd plus MTZ } \\
500 \mathrm{mg} \text { p.o. tid for } 2 \mathrm{~d} \\
\text { starting } 3 \mathrm{~h} \text { before }\end{array}$ \\
\hline Elshal (2018) & 163 vs 166 & Egypt & 2015-2017 & Fluoroquinolone & $\begin{array}{l}\text { Fluoroquinolone plus } \\
\text { aminoglycoside }\end{array}$ & $\begin{array}{l}\text { CIP } 500 \mathrm{mg} \text { p.o. bid } \\
\text { for } 3 \mathrm{~d} \text { starting the } \\
\text { day before }\end{array}$ & $\begin{array}{l}\text { CIP } 500 \mathrm{mg} \text { p.o. bid for } 3 \mathrm{~d} \\
\text { starting the day before plus } \\
\text { GEN } 160 \mathrm{mg} \text { i.v. just before }\end{array}$ \\
\hline
\end{tabular}

\section{Antibiotic prophylaxis in transrectal biopsy-alternatives to fluoroquinolones}

Regarding alternative options for antibiotic prophylaxis, two RCTs investigated aminoglycosides (gentamicin $3 \mathrm{mg} / \mathrm{kg}$ intravenously before biopsy and amikacin $15 \mathrm{mg} / \mathrm{kg}$ i.m. 1$2 \mathrm{~h}$ before biopsy), two RCTs investigated cephalosporins (ceftriaxone $1 \mathrm{~g}$ i.m. $0.5 \mathrm{~h}$ before biopsy and cefixime $400 \mathrm{mg}$ p.o./d for $3 \mathrm{~d}$ starting the day before biopsy), and three RCTs investigated fosfomycin trometamol (each $3 \mathrm{~g}$ p.o. $24 \mathrm{~h}$ before plus after biopsy, $3 \mathrm{~g}$ p.o. the night before biopsy, and $3 \mathrm{~g}$ p.o. $1 \mathrm{~h}$ before biopsy) versus fluoroquinolones. Aminoglycosides and cephalosporins were comparable with fluoroquinolones with regard to infectious complications, while fosfomycin trometamol led to a significantly reduced number of infections (RR 0.49, 95\% CI: 0.27-0.87) [1].

The value of fosfomycin trometamol was confirmed in three independent MAs, each including four to five studies comprising nonrandomized trials as well as studies conducted in countries with high fluoroquinolone resistance [10-12]. In contrast, in a recent large Canadian nested case-control study with $>9000$ patients, fosfomycin trometamol (single dose as well as two doses) was inferior to ciprofloxacin ( $3 \mathrm{~d}$ or single dose), which limits the generalizability of the use of fosfomycin trometamol [13]. In its implementing decision C(2020) 3966 final of June 2020, the European Commission sees a positive benefit in the use of fosfomycin trometamol as a PB antibiotic prophylaxis, but requested additional pharmacokinetic and pharmacodynamic studies to support the use of a second dose $24 \mathrm{~h}$ after the PB.

Targeted prophylaxis was originally introduced to offer an alternative antibiotic agent in case of fluoroquinolone resistance from a rectal swab/stool culture [14]. Fluoroquinolone resistance ranged from $18 \%$ to $83 \%$ in the six available RCTs included in the panel's SR [1]. However, four out of these six studies did not provide detailed information on the type, dosage, and duration of prophylaxis in the targeted prophylaxis group. It remains unclear whether nonfluoroquinolones were used in cases without fluoroquinolone resistance [1], meaning that targeted prophylaxis has been investigated only in the context of fluoroquinolone prophylaxis and there is no RCT available to date that does not use fluoroquinolones as a baseline prophylaxis. 
Augmented prophylaxis describes the use of two or more different classes of antibiotics. Although it contradicts the principles of antibiotic stewardship, the reason for its use is the broadening of the antibacterial spectrum to cover possible resistance to a single substance. However, out of the 10 available RCTs on augmented prophylaxis, eight studies combined a fluoroquinolone with another antibiotic. Only two older studies used alternative combinations (Table 1). Therefore, no recommendation can be made, on the basis of RCTs, as to which nonfluoroquinolone using combinations are superior to the use of monoprophylaxis. A recent non-RCT multicenter study has investigated the effect of local antibiogram-based augmented antibiotic prophylaxis. It reported that the use of an augmented antibiotic prophylaxis based on the local resistance patterns could reduce infectious complications by $53 \%$ relative to the historical rate, but again most combinations included a fluoroquinolone [15].

\section{Nonantibiotic strategies when transrectal biopsy is performed}

If a transrectal PB is performed, rectal preparation with povidone-iodine is highly recommended, as this is associated with a significantly reduced number of infectious complications (RR $0.50,95 \%$ CI: $0.38-0.65$ ) [2]. On the contrary, no advantage could be shown for the use of an enema [2]. Furthermore, the number of biopsy cores, use of local anesthesia in the form of periprostatic nerve block (PPNB), number of injections for PPNB, needle guide type, needle disinfection, and needle type had no influence on the rate of infectious complications [2].

Conflict of interest: Adrian Pilatz certifies that all conflicts of interest, including specific financial interests and relationships and affiliations relevant to the subject matter or materials discussed in the manuscript are the following: Gernot Bonkat is a company consultant for Vifor Pharma, Janssen, Cilag, Zambon, and IBSA; has received speaker honoraria from Vifor Pharma, Bionorica, and IBSA; and has received fellowship and travel grants from Astellas, Lilly, and Vifor Pharma. Riccardo Bartoletti is a company consultant for GSK; has received speaker honoraria from Becton and Dickinson; and has received fellowship and travel grants from IDI Pharma, Ipsen, Ab Mediac-procept, and MV Medical Solutions. Franck Bruyère has received speaker honorarium from Boston Scientific and Ipsen, and is a trail participant for CYSDUA. Tommaso Cai has received speaker honorarium from Zambon and Bayer. Suzanne Geerlings is a company consultant for and has received speaker honorarium from Vifor Pharma. Bela Köves is a company consultant for F. Hoffmann-La Roche and OM Pharma; has received speaker honorarium from Vifor Pharma and Bionorica; and has received fellowship and travel groups from the EAU. Sören Schubert is a company consultant for Achaogen, Bionorica, Janssen, Pfizer, RosenPharma, and Shionogi; has received speaker honorarium from Astra Zeneca; has participated in trials for Achaogen, Bionorica, Merlion, MSD, and Shionogi; and has received grants/research supports from Enteris, Helperby therapeutics, LeoPharma, and Vifor Pharma. Adrian Pilatz has received speaker honorarium from Vifor Pharma. Wout Devlies has participated in trials for Janssen and received a travel grant from Ipsen. Nicolas Mottet is a company consultant for Janssen, GE, BMS, Sanofi, and Astellas; has received speaker honoraria from Astellas, Pierre Fabre,
Steba, Janssen, and Ferring; and has received fellowships and travel grants from Astellas, Ipsen, Sanofi, Janssen, and Roche. Jeremy Grummet received speaker honorarium from Mundipharma, a travel grant from Astellas, and a research grant from Cancer Australia; he is the owner of MRI PRO Pty Ltd., an online training platform. Yuhong Yuan, Imran Omar, Benjamin Pradere, Rajan Veeratterapillay, and Tunde Mezei have nothing to declare.

Funding support: This work is supported by the European Association of Urology Guidelines Office.

\section{Appendix A. Supplementary data}

Supplementary material related to this article can be found, in the online version, at doi:https://doi.org/10.1016/j. eururo.2020.10.019.

\section{References}

[1] Pilatz A, Dimitropoulos K, Veeratterapillay R, et al. Antibiotic prophylaxis for the prevention of infectious complications following prostate biopsy: a systematic review and meta-analysis. J Urol 2020;204:224-30.

[2] Pradere B., Veeratterapillay R., Dimitropoulos K., et al. Non-antibiotic strategies for the prevention of infectious complications following prostate biopsy: a systematic review and meta-analysis. J Urol. In press. https://doi.org/10.1097/JU.0000000000001399.

[3] Roobol MJ, Steyerberg EW, Kranse R, et al. A risk-based strategy improves prostate-specific antigen-driven detection of prostate cancer. Eur Urol 2010;57:79-85.

[4] Venderink W, van Luijtelaar A, van der Leest M, et al. Multiparametric magnetic resonance imaging and follow-up to avoid prostate biopsy in 4259 men. BJU Int 2019;124:775-84.

[5] Yang L, Zhu Y, Tang Z, et al. Antibiotics may not decrease prostatespecific antigen levels or prevent unnecessary prostate biopsy in patients with moderately increased prostate-specific antigen levels: a meta-analysis. Urol Oncol 2015;33, 201.e17-24.

[6] Bennett HY, Roberts MJ, Doi SA, Gardiner RA. The global burden of major infectious complications following prostate biopsy. Epidemiol Infect 2016;144:1784-91.

[7] Berry B, Parry MG, Sujenthiran A, et al. Comparison of complications after transrectal and transperineal prostate biopsy: a national population-based study. BJU Int 2020;126:97-103.

[8] Grummet J, Gorin MA, Popert R, et al. "TREXIT 2020": why the time to abandon transrectal prostate biopsy starts now. Prostate Cancer Prostatic Dis 2020;23:62-5.

[9] Bonkat G, Pilatz A, Wagenlehner F. Time to adapt our practice? The European Commission has restricted the use of fluoroquinolones since March 2019. Eur Urol 2019;76:273-5.

[10] Freitas DMO, Moreira DM. Fosfomycin trometamol vs ciprofloxacin for antibiotic prophylaxis before transrectal ultrasonography-guided prostate biopsy: a meta-analysis of clinical studies. Arab J Urol 2019;17:114-9.

[11] Noreikaite J, Jones P, Fitzpatrick J, et al. Fosfomycin vs. Quinolonebased antibiotic prophylaxis for transrectal ultrasound-guided biopsy of the prostate: a systematic review and meta-analysis. Prostate Cancer Prostatic Dis 2018;21:153-60.

[12] Roberts MJ, Scott S, Harris PN, Naber K, Wagenlehner FME, Doi SAR. Comparison of fosfomycin against fluoroquinolones for transrectal prostate biopsy prophylaxis: an individual patient-data meta-analysis. World J Urol 2018;36:323-30. 
[13] Carignan A, Sabbagh R, Masse V, et al. Effectiveness of fosfomycin tromethamine prophylaxis in preventing infection following transrectal ultrasound-guided prostate needle biopsy: results from a large Canadian cohort. J Glob Antimicrob Resist 2019;17:112-6.

[14] Liss MA, Chang A, Santos R, et al. Prevalence and significance of fluoroquinolone resistant Escherichia coli in patients undergoing transrectal ultrasound guided prostate needle biopsy. J Urol 2011;185:1283-8.

[15] Concepcion RS, Schaeffer EM, Shore ND, Kapoor DA, Scott JA, Kirsh GM. The effect of local antibiogram-based augmented antibiotic prophylaxis on infection-related complications following prostate biopsy. Rev Urol 2019;21:93-101. 